\title{
Atendimento psiquiátrico a pacientes indígenas no Estado do Amazonas
}

Maximiliano Loiola Ponte de Souza ${ }^{1}$

Estima-se a existência de cerca de 206 sociedades indígenas no Brasil, distribuídas em 562 terras indígenas, correspondendo a uma população de cerca de 315 mil índios. Esses estão concentrados, em sua maioria $70 \%$ do total -, numa parcela da Amazônia Legal que engloba seis Estados brasileiros: Amazonas, Acre, Roraima, Rondônia, Mato Grosso e Pará.

A literatura nacional a respeito de transtornos mentais em populações indígenas (PI) no Brasil é escassa. As pesquisas nesta área encontram-se em fase embrionária, estando concentrada principalmente em grandes áreas temáticas, tais como alcoolismo (Aguiar e Souza, 2001) e suicídio (Erthal, 2001; Levcovitz, 1998). Não encontramos na literatura nacional dados sobre estudos naturalísticos a respeito de como vem sendo realizado na prática o atendimento psiquiátrico a esta população.

Dessa forma, este trabalho visa contribuir com essa questão complexa de pouco estudo: o atendimento psiquiátrico a PI. Tomamos por base o Estado do Amazonas, Estado que concentra a maior parte da população indígena nacional. Este trabalho é um primeiro olhar para as políticas de saúde mental direcionadas aos povos indígenas da Amazônia; outros estudos prospectivos estão em andamento.

Foram os objetivos específicos deste trabalho: a) caracterizar o perfil sociodemográfico, étnico e diagnóstico da população indígena que buscou atendimento psiquiátrico; b) caracterizar o atendimento dessa população, considerando: formas de utilização do serviço, freqüência de atendimento, multiplicidade diagnóstica e rotatividade de médicos assistentes.
Foi realizado um estudo retrospectivo de todas as PI que vieram para a cidade de Manaus e ficaram hospedadas na Casa de Saúde Indígena de Manaus (CASAI), com intuito de realizar atendimento psiquiátrico no Centro Psiquiátrico Eduardo Ribeiro (CPER, unidade psiquiátrica de referência estadual), no período de dezembro de 2000 a julho de 2002. As fontes de pesquisa utilizadas foram os arquivos da CASAI e os prontuários médicos do CPER. Na primeira fonte obtivemos informações sobre sexo, idade, estado civil, etnia, ocupação e área indígena de procedência das PI. Já na segunda, buscamos as seguintes informações: formas de utilização do serviço, freqüência de atendimento, multiplicidade diagnóstica e rotatividade de médicos assistentes.

Durante o período avaliado, 1.461 pacientes vieram para CASAI com o intuito de realizar atendimento médico em Manaus, mas apenas $11(0,75 \%)$ vieram encaminhados para avaliação psiquiátrica.

Considerando essa subpopulação, não houve diferenças quanto ao sexo $(54,5 \%$ - 6 do sexo feminino - e 45,5\% - 5 do sexo masculino). Suas idades variaram de 17 a 70 anos, com idade média de 36,1 anos, mediana e moda igual a 29 anos. Eram em sua maioria não-casados $(63,7 \%)$. Em relação à ocupação declarada, a maioria era de lavradores $(63,63 \%$; 7) 2 eram estudantes, 1 doméstica e 1 zelador da CASAI. Esses pacientes pertenciam a sete etnias diferentes: Santaré (2), Baniwa (2), Jamamadi (1), Hexkariano (1), Apuriña (1), Mura (1), Yanomami (1), Palmari (1), Mundururu (1).

\footnotetext{
Médico Psiquiatra. Professor do Curso de Psicologia do Centro Universitário Lutero de Manaus da Universidade Luterana do Brasil. Médico do Centro Psiquiátrico Eduardo Ribeiro, da Secretaria de Saúde do Estado do Amazonas.

Endereço para correspondência:

Rua B, Quadra B, Casa 249, Conjunto Parque das Palmeiras I, Manaus, AM - CEP 69000-000.

E-mail: souzamaximiliano@hotmail.com
} 
As PI estavam em tratamento no CPER em um período que variava de 5 a 51 meses (média 15,38; desviopadrão de 15,88 ). Considerando um período de seis meses, a média do número de retornos por paciente foi de 1,03 (desvio-padrão de 0,5; extremos de 0,6 e 2,4). Em relação ao motivo do atendimento psiquiátrico, todos os pacientes apresentavam história recente de agitação psicomotora e/ ou agressividade explícita. Aproximadamente metade dos pacientes $(6 ; 54,54 \%)$ nunca foram atendidos ambulatorialmente e apenas $2(18,8 \%)$ foram atendidos exclusivamente nessa modalidade de tratamento. Excluindo os pacientes que foram atendidos uma única vez no serviço (2) e um outro paciente, nenhum paciente foi atendido pelo mesmo médico duas ou mais vezes, recebendo diferentes diagnósticos, que variaram em número de 2 a 4 . Os principais diagnósticos foram do grupo da esquizofrenia e outros transtornos psicóticos e transtornos mentais orgânicos.

Mesmo reconhecendo a limitação dos dados obtidos, principalmente devido à extensão reduzida do universo estudado, ao caráter retrospectivo e documental da pesquisa e à ausência de instrumentos padronizados de diagnóstico, pudemos inferir que o atendimento psiquiátrico a PI no Estado do Amazonas é bastante deficiente. Essa conclusão é baseada no fato de que a principal modalidade de atendimento das PI é o serviço de pronto-atendimento, cujo enfoque é emergencial e caracterizado por atendimento por médicos plantonistas em sistema de rodízio, gerando dessa forma uma multiplicidade diagnóstica, baixo vínculo com um profissional de referência e baixa aderência ao tratamento ambulatorial, que pode ser evidenciado pelo baixo número médio de retornos para um período de seis meses, principalmente se considerarmos que os atendimentos eram essencialmente motivados por quadros de agitação e agressividade explícita.

Em relação ao perfil diagnóstico das PI, acreditamos que não seria adequado procedermos uma generalização dos dados obtidos, considerando as limitações da pesquisa. Por outro lado, o fato de a motivação da consulta ser essencialmente associada à agitação psicomotora e/ou à agressividade parece evidenciar que os pacientes encaminhados são aqueles cujo comportamento tornou-se por demais disruptivo, sem condições de manejo na sua região de origem. Este dado pode sinalizar pelo menos duas situações explicativas.

A primeira hipótese explicativa seria que a maioria dos quadros psiquiátricos puderam ser adequadamente manejados ao nível das aldeias pela utilização de técnicas da medicina tradicional, associadas a uma maior tolerância por parte das comunidades indígenas com o comportamento disfuncional de alguns de seus membros. Dessa forma, apenas os quadros mais graves, que extrapolariam a capacidade continente local, seriam encaminhados para avaliação médica externa.

Outra possibilidade seria uma limitada capacidade de identificação de transtornos mentais em fases iniciais por profissionais que atendem as PI em nível regional. Essa limitação poderia estar relacionada tanto com a formação técnica dos profissionais como com as dificuldades de acesso às comunidades, tanto do ponto de vista geográfico como cultural.

Parece-nos clara a necessidade de estudos prospectivos e de seguimento, com uso de instrumentos padronizados de pesquisa, para que os dados aqui inferidos possam ser ratificados ou refutados, com o objetivo de buscar estratégias que possam viabilizar uma melhoria na qualidade ao atendimento psiquiátrico aos pacientes indígenas do Estado do Amazonas.

Como reflexo inicial dos resultados aqui demonstrados, o autor deste artigo fez acordo com a coordenação da CASAI com o intuito de tornar-se o profissional de referência das PI encaminhadas para tratamento psiquiátrico em Manaus no CPER, visando pelo menos minimizar a baixa aderência ao tratamento ambulatorial e a multiplicidade diagnóstica pela tentativa de promoção de um vínculo terapêutico mínimo associado com a manutenção do mesmo profissional em diferentes atendimentos na instituição.

\section{Agradecimento}

Aos funcionários da Casa de Saúde Indígena de Manaus e aos funcionários do Serviço de Arquivo Médico do Centro Psiquiátrico Eduardo Ribeiro.

\section{Referências bibliográficas}

Aguiar, J.I.A.; SouzA, J.A. - Alcoolismo em População Terena no estado do Mato Grosso do Sul. Impacto da sociedade envolvente. Anais do Seminário de alcoolismo e DST/AIDS entre os Povos Indígenas, 2001.

Erthal, R.M. - O Suicídio Tikúna no Alto Solimões: Uma Expressão de Conflitos. Cad Saúde Pública 17(2): 299-311, 2001.

Levcovitz, S. - Kandiré: O Paraíso Terral. O suicídio entre os índios guaranis do Brasil. Te Cora Editora, Belo Horizonte, 1998. 